\title{
An experimental investigation on the effect of adhesive distribution on strength of bonded joints
}

\author{
A. P. Pisharody * (D, B. Blandford, D. E. Smith and D. A. Jack
}

\author{
*Correspondence: \\ akash_pisharody1@baylor. \\ edu \\ Mechanical Engineering \\ Department, Baylor \\ University, Waco, TX, USA
}

\begin{abstract}
Adhesive joints are widely used due to their higher strengths, lower weights, lesser expenses and ease of fabrication than other methods of joining. Hence, they are used extensively in aerospace and automobile industries. High quality bonds require the use of fixtures which are essential to ensure proper curing and to attain uniform thickness. Improper adhesive application and method of fixturing can cause irregularities in the distribution of the adhesive along the overlap which could affect the joint strength. This is especially critical for aerospace components as the replacement of parts can be costly and time consuming. This paper presents a nondestructive test (NDT) methodology to quantify the bonded joints where the adhesive does not completely cover the overlap area. Single lap adhesive joints with carbon fiber adherents were fabricated using a two-part epoxy based adhesive. The adhesive region was fabricated to have various shapes including elliptical and circular of different sizes and a joint with full coverage for comparison. Polytetrafluoroethylene (PTFE) cutouts were used to mask regions of adhesive to achieve the desired coverage pattern. After fabrication all samples were ultrasonically scanned with a $10 \mathrm{MHz}$ spherically focused immersion transducer using pulse-echo ultrasonics to determine the actual as tested adhesive distribution shape. The scans were able to resolve the shape of adhesive distribution across the overlap region of $25.4 \times 25.4 \mathrm{~mm}$ and were correlated with the actual adhesive distribution at the interface after lap shear tests. Lap shear tests were then performed on the samples fabricated and the samples were loaded to failure. It was found that the shape and the orientation of the adhesive shape relative to the loading direction had an effect on failure strength.
\end{abstract}

Keywords: Bonded joints, Ultrasonic scanning, Adhesive distribution, Nondestructive testing, Woven carbon-fiber composite laminates

\section{Introduction}

Adhesive bonding is a cost effective and weight efficient method to join materials. It also provides a lower weight, more versatile, corrosion resistant and fatigue resistant alternative to bolting and riveting [1] which makes it highly attractive in the automotive and aeronautical industries. The need of fuel efficiency and higher speed vehicles have made the use of composite materials popular. Joining composite parts with conventional methods such as bolting or riveting causes defects such as de-laminations often caused during the hole drilling process [2]. Adhesive bonding helps to eliminate this issue. Joints can be 
fabricated in various configurations and single lap joints are widely used due to their efficiency and simplicity [3] and often employed when testing adhesive bond properties.

Despite its benefits, adhesive bonds are prone to defects. Common defects in adhesive bonding are voids, inclusions, kissing bonds and cracks, all of which cause a reduction in joint strength [1]. Many researchers have studied the effect of defects on the strength of adhesive joints. An initial study on the effect of bond line defects such as gaps and flaws was performed by Hart-Smith [4]. Heslehurst [5] classified defects into two broad categories, de-bonds and weak bonds, and used holographic interferometry to identify them. Berry et al. [6] investigated the effect of circular defects, centered along the bond length, on joint strength. Moura et al. [7] studied the effect of strip defects, centrally placed along the overlap length and across the width, on joint strength. They found that as the size of the defect along overlap increases, the bond strength reduces due to the higher stresses generated towards the end of the overlap. Engerer et al. [8] studied 'band' lap joints under tensile loading. Band lap joints are formed using intermittent layers of adhesive over overlap length or area [9].

Ultrasonic testing is a widely used nondestructive method for detecting flaws within a material and at material interfaces [10]. Ultrasonic measurements are made by transmitting and receiving high frequency sound waves [11]. Analysis of the measured data provides results which can help identify the presence of material boundaries and/or defects [12]. Pulse echo techniques have been widely used for the inspection of bonded joints especially when defects such as voids or cracks are involved since it does not require access to both sides of the joint [13]. One of the earlier works using the pulse echo ultrasound technique was done by Tattersall [14] in which weak bonding along the interface was detected. Shiuh-chan Her and Yi-Chun Li [15] used ultrasound to detect weak bonds with an epoxy adhesive by varying hardener mixing ratios using the differences in frequency response to evaluate the interfacial stiffness, which was used to find the bond strength by correlation. De Freitas et al. [16] used acoustic emission to detect weak bonds by monitoring the de-bonding mechanisms in mode I loading using a double cantilever beam test. Various other researchers have used ultrasound to study adhesive bonds [17-20]. Korzeniowsk [21] for example used ultrasound to detect the shape and size of defects which were embedded in the adhesive bond. It was done using the difference in the intensity of sound reflected from the interface, using A-scan data, depending on whether the adhesive is present at the interface. The current study used ultrasonic $\mathrm{C}$-scans for detecting shape and size of adhesive coverage which gave a better resolution of the adhesive distribution.

Gaps in the bond line frequently occur due to a lack in adhesive coverage and are therefore often treated as a defect [22]. These gaps cause the applied load to be re-distributed to the surrounding adhesive thus increasing local stress in these regions [23]. Bonding equipment such as fixtures are recommended when adhesives require proper contact pressure and/or heat application [24]. An improper selection or design of bond joint fixturing or negligence on the part of the technician during the application process can produce improper adhesive coverage in the bond overlap region especially when liquid and paste adhesives are employed. A loss of bond coverage during fabrication can cause gaps in the bond region that are not able to transmit the required stresses between the adherents. The current study focusses on such scenarios where the adhesive does 
not cover the entire region of the bond area. The shape of the adhesive coverage was defined by pre-determined circular and elliptical shape using Polytetrafluoroethylene (PTFE) sheet cut-outs, as these shapes are natural when a viscous fluid spreads on a surface under pressure. Prior to bond testing, the bond region was scanned ultrasonically to determine the actual adhesive distribution shape which was then correlated to the expected shape and size of the adhesive after the tensile tests. Further, the scan data can be used to generate 3-D (Three dimensional) models for Finite Element analysis.

\section{Experimental work}

\section{Joint fabrication, dimensions and testing}

The adherents used in the study were taken from woven carbon-fiber composite laminate plates composed of plain weave carbon fiber fabric in a two-part epoxy (Proset INF114/INF-211) matrix. The composite plates were fabricated in house using a vacuum bagging and resin infusion process. The carbon fiber weaves were laid up in $[0 /+45 / 0]_{3}$ configuration, consisting of 9 layers in total. The manufacturer recommended cure cycle was followed. Test coupons were sectioned from the laminated composite using a circular tile saw. Single lap joints were made for testing following the configuration as detailed in Fig. 1. The lap joint design samples were based on ASTM (American Society for Testing and Materials) D-1002 standard [25]. All joints had an adherent overlap region of area of $25.4 \times 25.4 \mathrm{~mm}$. A two-part epoxy adhesive (Fiber Glast 1101, Ohio, United States) was used for bonding. The adherent surfaces were prepared trough abrasion using a 320 grit sand paper on an orbital sander followed by an iso-propyl alcohol wash based on the adhesive manufacturers recommendation. PTFE films of $0.2 \mathrm{~mm}$ thickness were cut to form the bond joint templates appearing in Fig. 2b. The PTFE film also acted as a spacer for maintaining a bond line thickness of $0.2 \mathrm{~mm}$. Bond joint test samples were then fabricated using a fixture to maintain a controlled contact and specimen straightness through the adhesive cure cycle. The PTFE film templates remain in the bonded region after curing of the adhesive, but as they cannot bond with epoxy resin, they carry no shear load, and this does not contribute to the load carrying capacity of the overall bonded region. The test samples prepared for the bond joint lap shear tests are detailed in Table 1. The part number for each of the configurations is enclosed in a bracket along-side each entry in the table for ease of identification during discussion. Test samples were made with bonds having circular shapes and elliptical shapes, with two different orientations and three different sizes, in addition to a bond samples with

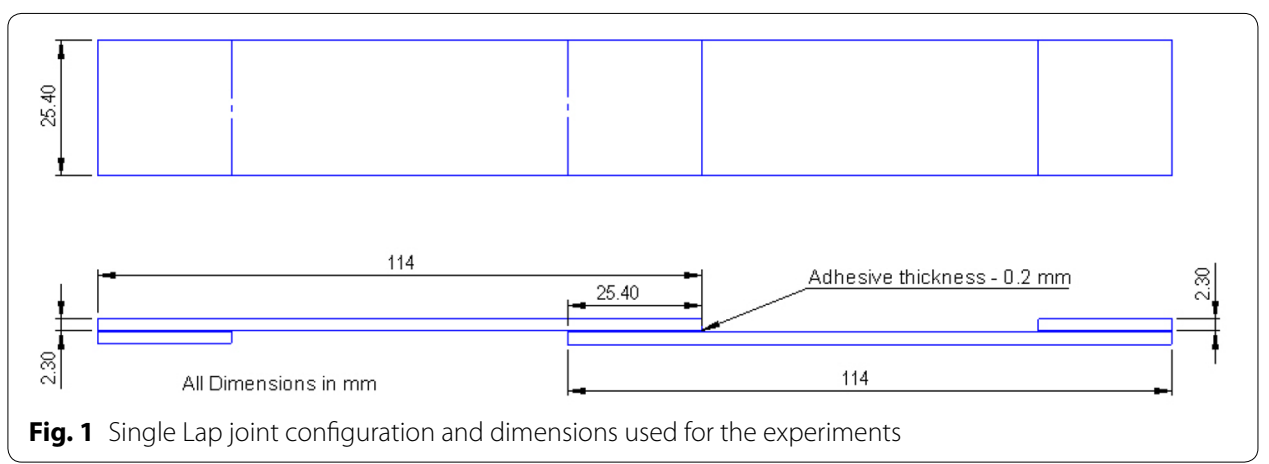




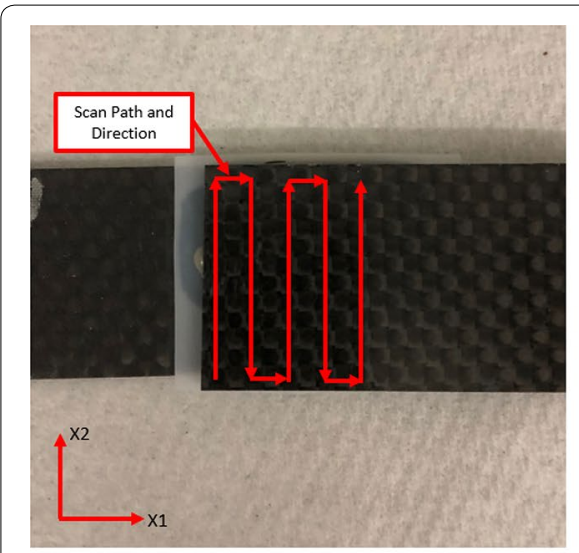

a

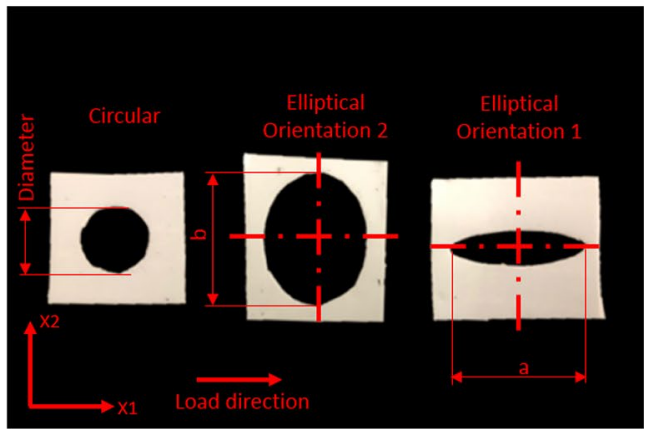

b

Fig. 2 a Ultrasonic scan path and direction and b PTFE cut-outs used to produce the required adhesive shape

Table 1 Summary of experimental trials (joint identification in brackets)

\begin{tabular}{llll}
\hline & Size level $\mathbf{1}$ & Size level 2 & Size level 3 \\
\hline Complete coverage & $25.4 \times 25.4$ & & \\
& $(R)$ & & \\
Circular & Diameter 25.4 & Diameter 19.05 & Diameter 16.35 \\
& $(C 1)$ & $(C 2)$ & $(C 3)$ \\
Elliptical orientation 1 & $a=25.4, b=19.05$ & $a=25.4, b=12.7$ & $a=25.4, b=6.35$ \\
& $(E 1-1)$ & $(E 1-2)$ & $(E 1-3)$ \\
Elliptical orientation 2 & $a=19.05, b=25.4$ & $a=12.7, b=25.4$ & $a=6.35, b=25.4$ \\
& $(E 2-1)$ & $(E 2-2)$ & $(E 2-3)$ \\
\hline
\end{tabular}

All dimensions in $\mathrm{mm}$

a-length along overlap length, $b$-distance along width

full coverage. The tensile bond lap shear testing was performed at room temperature using an MTS Q-Test 100 tensile testing machine having a load cell rating of $100 \mathrm{KN}$ and at a loading rate of $0.02 \mathrm{~mm} / \mathrm{s}$ based on the ASTM D-1002 standard [25].

\section{Ultrasonic scanning}

A custom in-house immersion ultrasonic scanning system paired with a custom LabView code is used to scan the bonded laminates. For the present study, a $10 \mathrm{MHz} 0.5$ in spherically focused ultrasonic immersion transducer (Olympus, Massachusetts, United States) with a $38 \mathrm{~mm}$ (1.5 in.) nominal focal length was employed. A pulser/receiver (US Ultratek, California, United States) is used to sample the ultrasonic signal at a rate of $160 \mathrm{MHz}$. The transducer is mounted to translation stages (Velmex, New York, United States). A parallel coupled Bi-slide provides motion in the X1-axis (index direction) and a single Bi-slide provides $\mathrm{X} 2$-axis (scan direction) motion. Both the $\mathrm{X} 1$-axis and $\mathrm{X} 2$-axis have a resolution of $0.0013 \mathrm{~mm} / \mathrm{step}$ however a raster resolution of $0.2 \mathrm{~mm} / \mathrm{scan}$ location was used for all the scans in the current study. The ultrasonic transducer frequency and resolution were selected based on previous experience [26] and determined to provide adequate resolution to capture the features. The X3-axis of the translation stage has a resolution of $0.0013 \mathrm{~mm} / \mathrm{step}$ and is used to manually focus the transducer prior to 
scanning. Adjustable levelling feet as shown in Fig. 3 are used to level the specimen so that its top surface is normal to the axis of the transducer during the entire scan. Figure 3 shows the top view of the immersion scanning setup. Figure 4a shows a schematic representing the various components of the scan setup and Fig. $4 \mathrm{~b}$ describes the scanning process. The scanning axes and path are shown in Fig. 2a. The origin is defined as the point where the scan starts.

\section{Results and discussions}

\section{Joint strength tests}

Lap shear tests on a full coverage bond samples exhibited a brittle and symmetric adherent failure mode as shown in Fig. 5a. Microscopy images Fig. 5b were generated using an optical microscope of the failed surfaces, and they indicate that the adhesive pulls out the fibers during failure. Prior researchers [27-29] have shown that both the peel and shear stresses are maximum near the end of the overlaps on single lap joints in lap shear tests. In addition, finite element analysis [30] reveals that a higher stress region in the adherent near the interface. Also it has been found by Kupski et al. [31] that if fibers oriented at $90^{\circ}$ are adjacent to the bond line, it results in an adherent failure instead of a cohesive failure when fibers are oriented at $0^{\circ}$, due to higher peel stresses. Since woven composites used in the current study had a ply of $0 / 90^{\circ}$ orientation adjacent to the interface, higher peel stresses may be generated by the fibers oriented at $90^{\circ}$, leading to crack propagation into the adherent. These could be the reasons for the failure mode observed. The same failure mode was observed in all the adhesive shape configurations used in this study. The failure modes for elliptical and

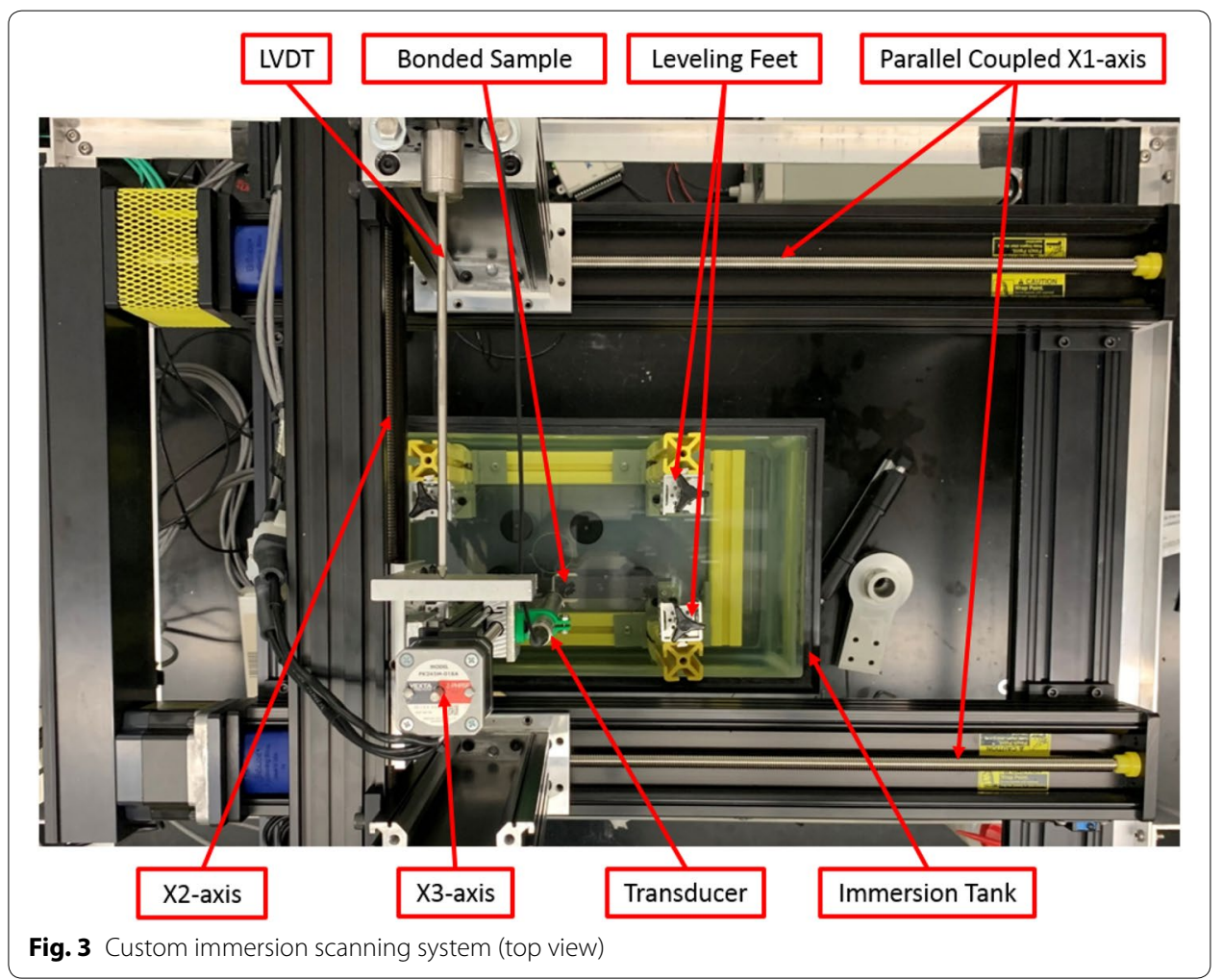




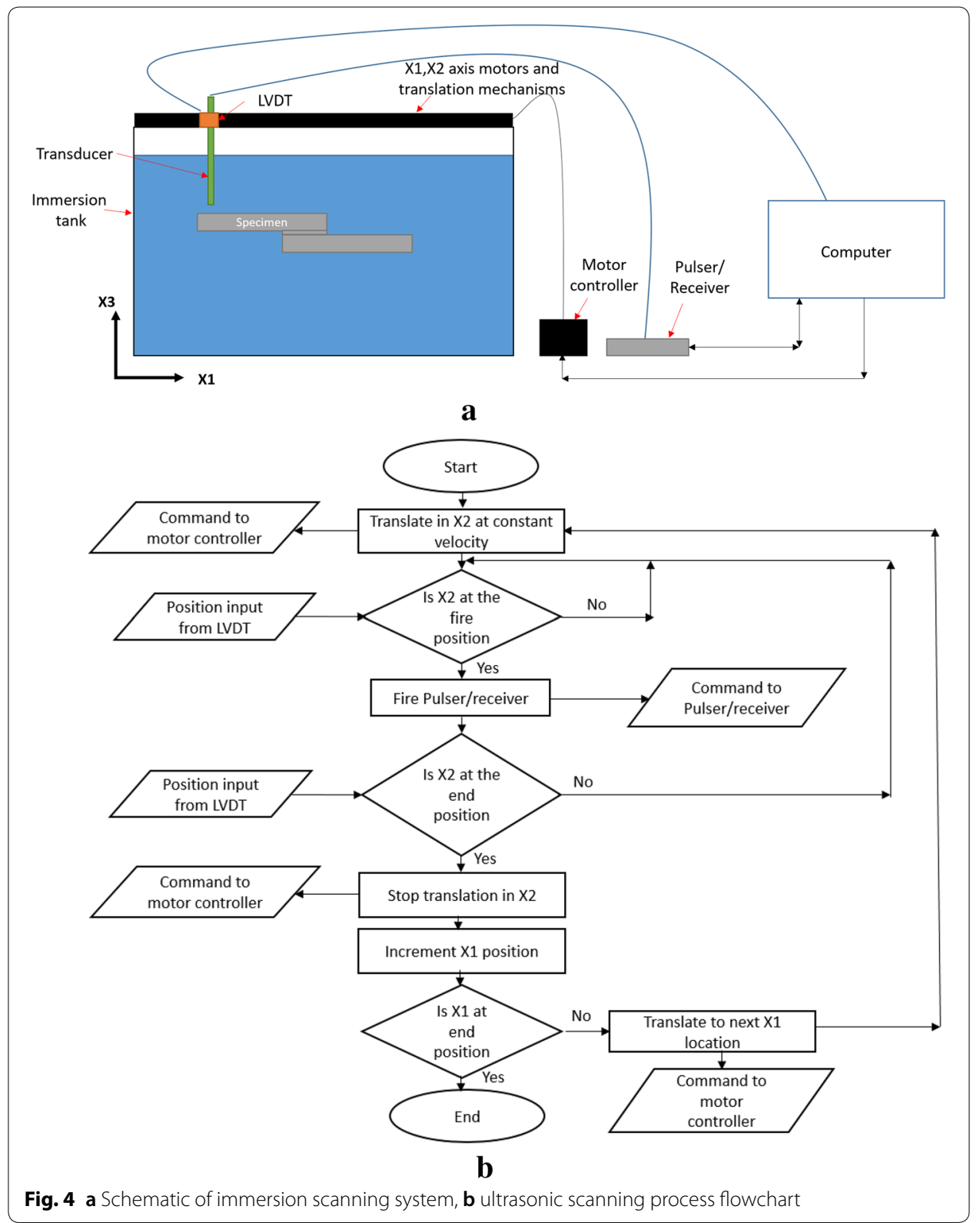

circular shapes are shown in Fig. 12. A summary of the failure load for the lap shear joint for each of the configurations is as shown in Fig. 6. For each set presented it is the compilation of three separate tests for a total of 30 lap shear joint strength tests. The error bars presented in the Figs. 6 and 7 are of the standard deviation of the three tests. Based on the failure loads listed in Fig. 6, the joint with complete coverage of adhesive was found to have the highest average strength as expected. The average failure load decreased as the coverage area decreases in each of the shapes as would be expected. The average shear stresses of the joints paired by their size levels is shown in Fig. 7. The average shear stress is defined as the average failure load divided by the as manufactured bonded area. The average shear stress increases as the size of 


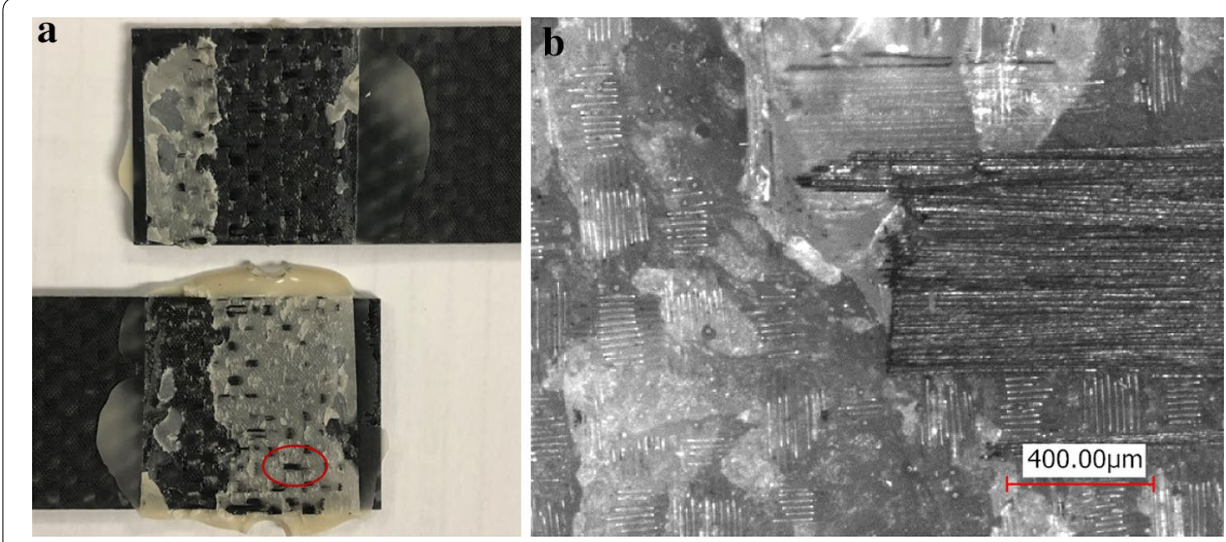

Fig. 5 a Failed surface as observed in joints having complete adhesive coverage. b Magnified image of failed adhesive surface from the region highlighted in $\mathbf{a}$, showing adherent failure

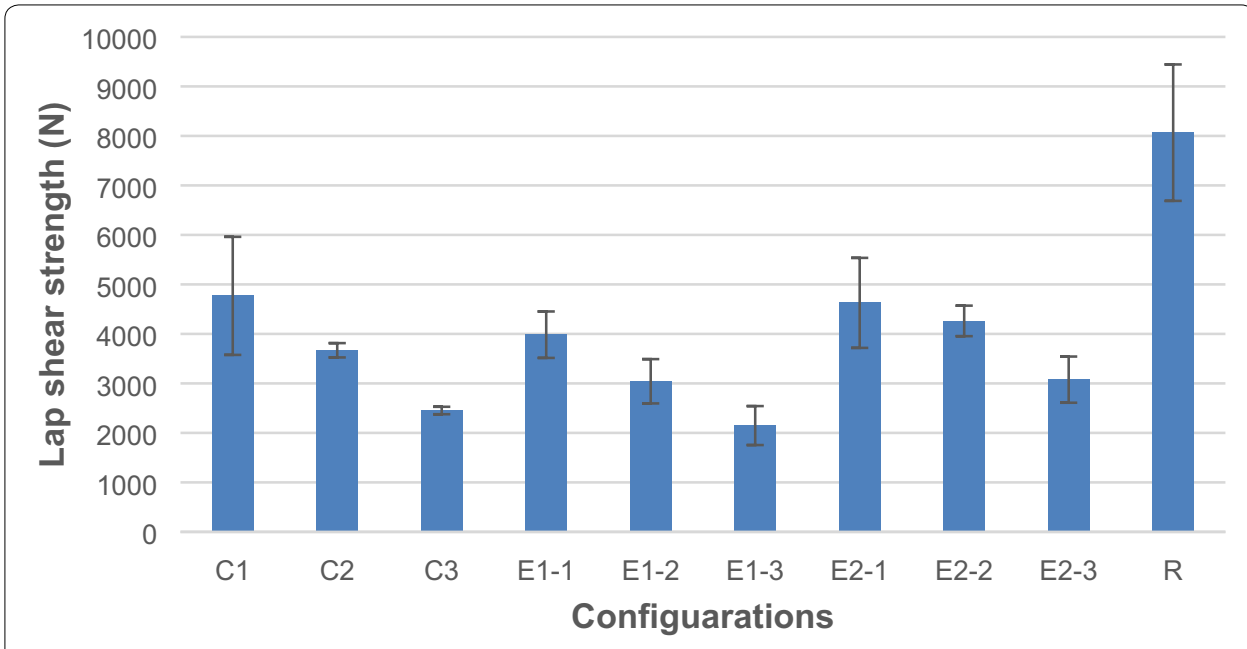

Fig. 6 Lap shear strengths after tensile testing the specimen in various configurations

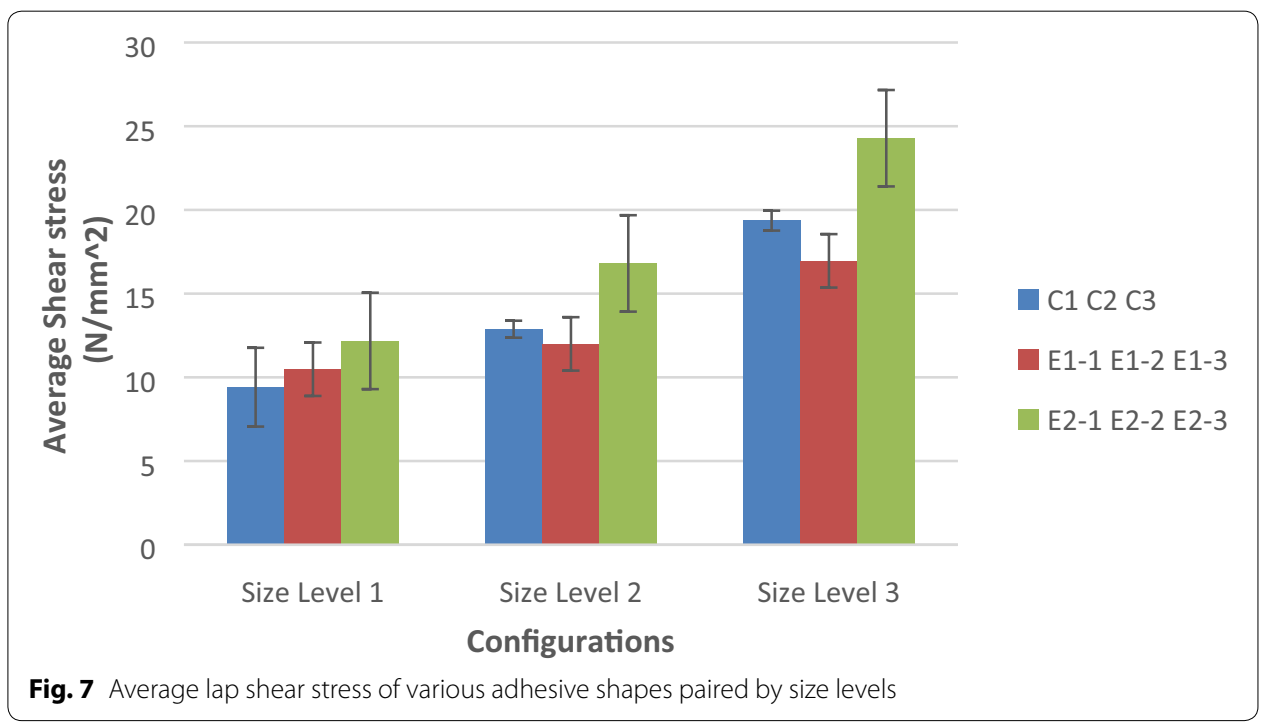


the bonded region in each configuration decreases. This could be because there is a larger area of the adhesive which allows for a larger internal stress gradient (see e.g. [26]). This gradient allows higher stresses to occur near the edges of the adhesively bonded region with less load being carried in the central region of the bond. Despite the average shear stress in the ellipse of orientation 2 being consistently higher than that of orientation 1, the failure strengths are higher for orientation 2. Another factor to be considered is the presence of the adhesive along the traverse direction of load applied as in the case of orientation 2 as compared to orientation 1. As the failure propagates from the ends, it encounters more resistance in the case of orientation 2 than otherwise. This indicates that the distribution of the adhesive along the traverse direction to load application influences the joint strength. A detailed finite element analysis would be required to assess the actual stress distribution states along the interface which will help clearly explain the cause of lower strength. The loaddisplacement curves for various configurations are compared in Fig. 8 In each of the cases, the energy absorbed by the joints increases as the coverage area increases, with the joint having complete coverage taking the lead. The energy absorbed by the elliptical shaped adhesive of E1-1 configuration $(a=25.4 \mathrm{~mm}, b=19.05 \mathrm{~mm})$ is less as compared to that of elliptical shaped adhesive of E2-1 configuration $(a=19.05 \mathrm{~mm}$, $\mathrm{b}=25.4 \mathrm{~mm}$ ) as seen in Fig. 8d. Also, the joints with elliptical shaped adhesive of orientation 1 fail at lower global displacements than other configurations.
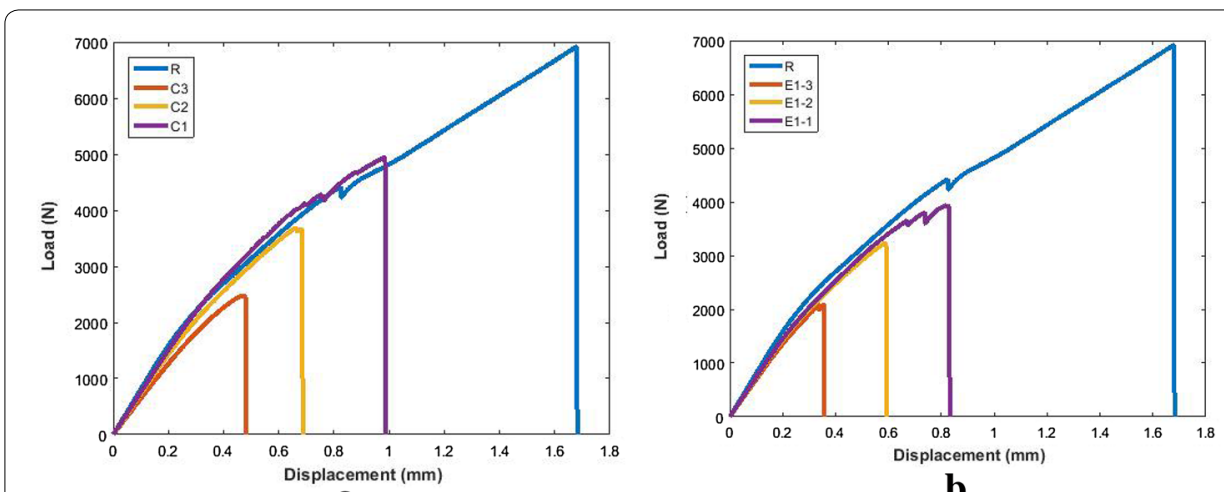

$\mathbf{a}$
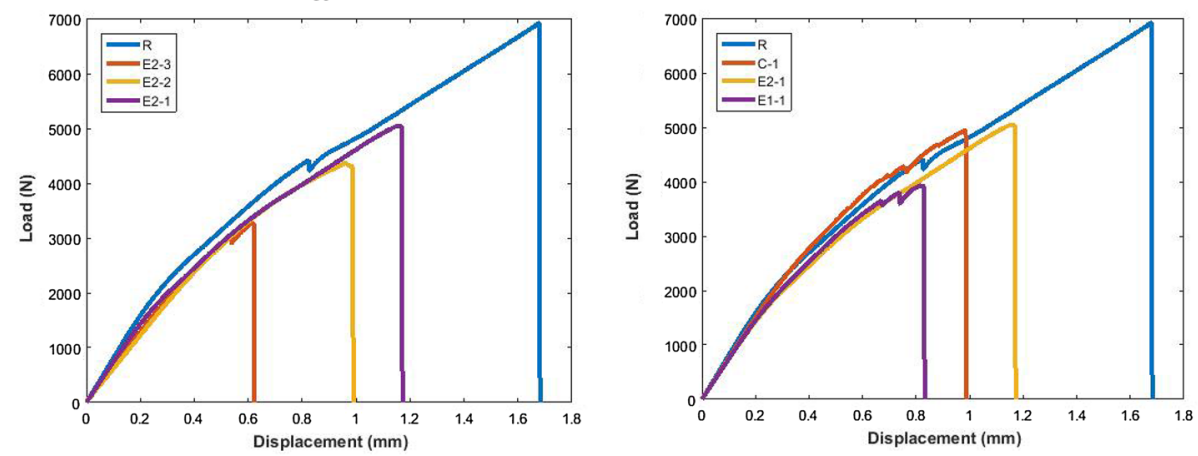

c

d

Fig. 8 Load displacement curves a Circular shaped adhesive, $\mathbf{b}$ elliptical shaped adhesive of orientation 1, c elliptical shaped adhesive of orientation 2, $\mathbf{d}$ comparison between complete coverage, circular diameter $25.4 \mathrm{~mm}$, elliptical $\mathrm{a}=19.05, \mathrm{~b}=25.4 \mathrm{~mm}$, elliptical $\mathrm{a}=25.4, \mathrm{~b}=19.05 \mathrm{~mm}$ 

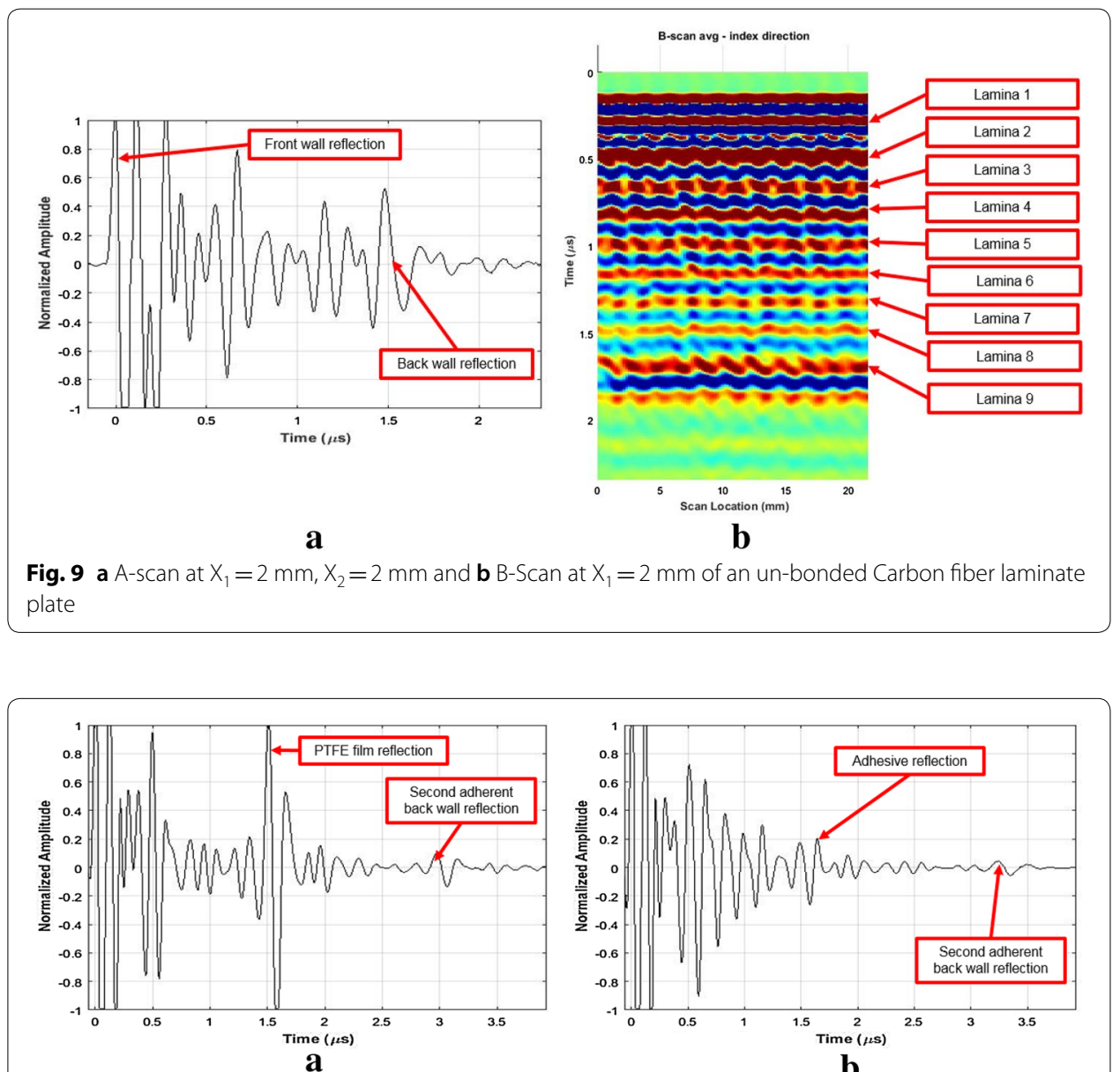

Fig. 10 Comparison of A-scans at overlap region of the adhesive overlap in the $\mathbf{a}$ PTFE film region and the $\mathbf{b}$ adhesive region

\section{Ultrasonic scanning}

The A-scan and the B-scan of a typical un-bonded Carbon-fiber laminate measuring $2.3 \mathrm{~mm}$ in overall part thickness is shown in Fig. 9 where the front and back walls of the sample cause distinct peaks as shown. Other peaks represent reflections from individual plies in the composite. The location of individual plies can be seen in the B-scans. The intensity of sound reflected decreases because of attenuation of sound due to reflections from the preceding plies. The A-scans of specimen $\mathrm{C} 2$ from the PTFE film region $\left(X_{1}=2 \mathrm{~mm}, X_{2}=2 \mathrm{~mm}\right)$ and the adhesive region $\left(X_{1}=12 \mathrm{~mm}, X_{2}=10 \mathrm{~mm}\right)$ appear in Fig. 10. A distinct peak appears as the sound reflects from the PTFE film which is caused by a high acoustic impedance mismatch between the carbon fiber laminate and PTFE. An A-scan in the region where the adhesive is present shows a relatively smaller peak at the same interface. This is due to the better acoustic impedance match between the adhesive and carbon fiber epoxy laminate since both the adhesive and the matrix are epoxy resins. The B-scans and C-scans are formed from multiple A-scan data at each location along the ultrasonic sweep. Figure 11 shows a B-scans of the same specimen mentioned above along $X_{1}=2 \mathrm{~mm}$ and $X_{1}=12 \mathrm{~mm}$. The adhesive and the PTFE film positions were identified after the ninth lamina position. 


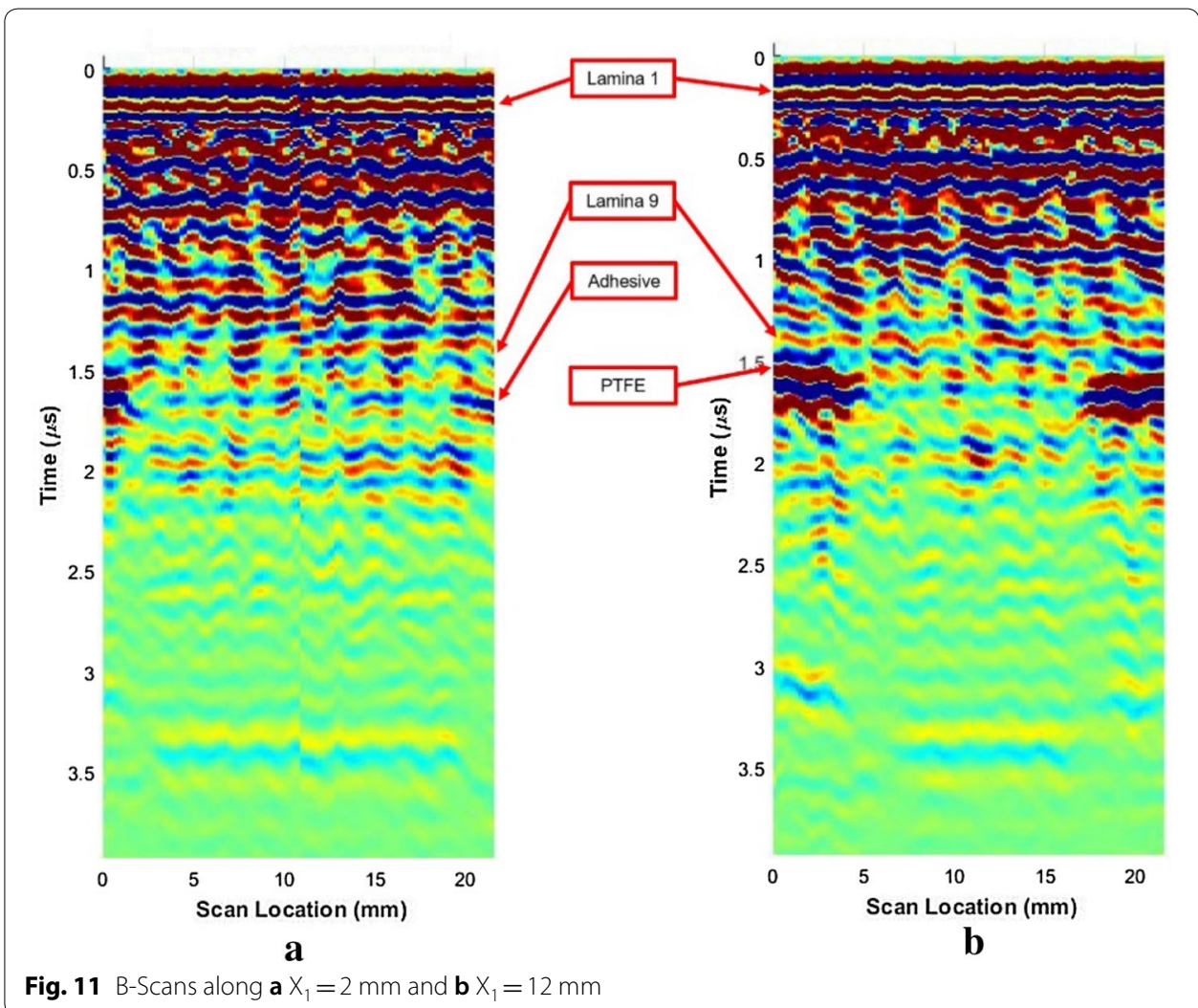

C-scans are evaluated to identify the shape and distribution of the adhesive for each sample, where the results appear in Fig. 12. The scans show a red region around a blue colored region. The red region indicates a higher intensity of sound wave reflection at a material interface which indicates the presence of the PTFE film. Alternatively, the blue region indicates the presence of the adhesive which has a lower intensity of reflected sound as discussed above. It can be clearly seen form the broken interface in Fig. 12 that there is a correlation between the geometry of the adhesive observed at the bond interface during $\mathrm{C}$-scans and the actual broken surface.

\section{Conclusions}

The effect of the adhesive distribution throughout the overlap region in bonded joints are studied. A joint with complete adhesive coverage over the entire overlap region would be expected to have the highest strength. Improper application of adhesive may occur during fabrication and may result in an improper distribution of adhesive. Three adhesive size levels and two different shapes namely circular and elliptical, with the elliptical shape having with two orientations, were studied. The study on lap shear strength reveals that the distribution of the adhesive along the traverse direction to load application has an effect on the bond strength. The specimen having complete coverage of the adhesive along the traverse direction, namely the circular shape having its diameter, and the elliptical shape having one of the axis lengths equal to the bond width, exhibited a larger lap shear strength. Meanwhile the elliptical shape with its major axis oriented along the load application direction had the least strength as compared to the other orientations, despite 

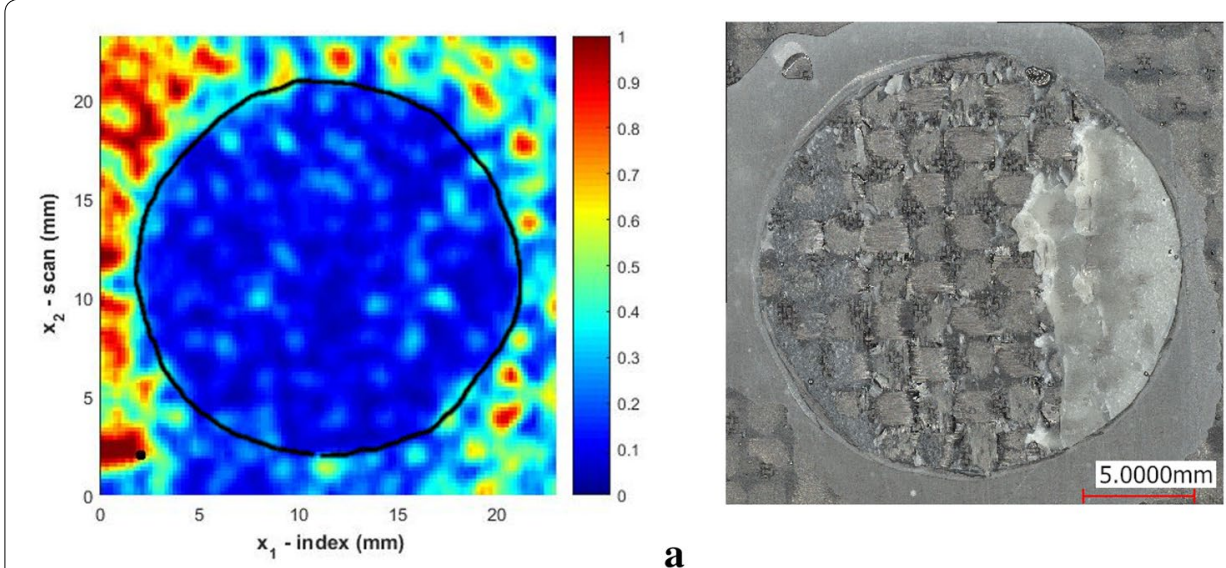

$\mathbf{a}$
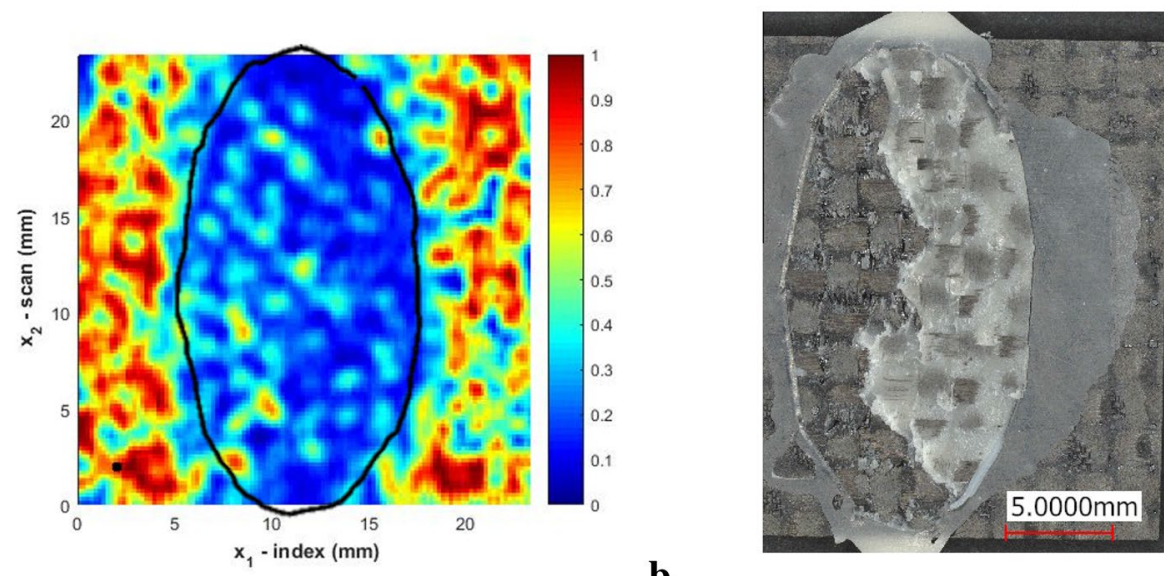

b

Fig. 12 C-Scan images at the bondline and comparison with their corresponding broken surfaces of a circular $19.05 \mathrm{~mm}$, b elliptical $\mathrm{a}=12.7, \mathrm{~b}=25.4 \mathrm{~mm}$ (the black outlines on the left images are the adhesive outlines traced from the optical images on the right.)

having the same coverage area. Further analysis using finite element modelling would be required to quantify the variations in stress distributions in each of the cases. Ultrasonic scanning was performed to identify the shapes of adhesive distribution in the bond overlap region. Comparison of the failed specimen after the lap shear tests, revealed a correlation between the shapes identified using ultrasonic C-scans. These scan images can be used to provide useful bond geometry data for generating 3-D models of adhesive distribution which can be analyzed using finite element methods.

\section{Abbreviations}

NDT: non destructive testing; PTFE: polytetrafluoroethylene; 3D: three dimensional; ASTM: American Society for Testing and Materials.

\section{Acknowledgements}

The authors would like to thank L3-Harris, under whose funding they were able to conduct this research work.

\section{Authors' contributions}

APP who is a Ph.D. student at Baylor University is the main author of this paper. BB who is also a Ph.D. student and the second author, provided assistance with the ultrasonic scans and analysis. DES and DAJ are the supervisors of the main and the second author, who provided the guidance for this work. All authors read and approved the final manuscript.

\section{Funding}

This research was funded by L3-Harris, Waco, Texas, USA. 
Availability of data and materials

The data supporting the findings are presented in the manuscript.

\section{Competing interests}

The authors declare that they have no competing interests.

Received: 9 August 2019 Accepted: 6 November 2019

Published online: 20 November 2019

\section{Bibliography}

1. Ebnesajjad S. Handbook of adhesives and surface preparation. Elsevier; 2011. https://doi.org/10.1016/c2010-0-65918-9.

2. Silva P, Matos JE, Durão LM. Analysis of damage outcome in the strength of polymer composite materials. J Compos Mater. 2019;53:547-60. https://doi.org/10.1177/0021998318787855.

3. Banea MD, da Silva LFM. Adhesively bonded joints in composite materials: an overview. Proc Inst Mech Eng Part J Mater Des Appl. 2009;223:1-18. https://doi.org/10.1243/14644207JMDA219.

4. Hart-Smith L. Further developments in the design and analysis of adhesive-bonded structural joints. In: Kedward K, ed. Join. Compos. Mater., 100 Barr Harbor Drive, PO Box C700, West Conshohocken, PA 19428-2959: ASTM International; 1981, p. 3-3-29. https://doi.org/10.1520/stp33472s.

5. Heslehurst RB. Observations in the structural response of adhesive bondline defects. Int J Adhes Adhes. 1999;19:133-54. https://doi.org/10.1016/S0143-7496(98)00029-3.

6. Berry NG, d'Almeida JRM. The influence of circular centered defects on the performance of carbon-epoxy single lap joints. Polym Test. 2002;21:373-9. https://doi.org/10.1016/S0142-9418(01)00099-X.

7. de Moura MFSF, Daniaud R, Magalhães AG. Simulation of mechanical behaviour of composite bonded joints containing strip defects. Int J Adhes Adhes. 2006;26:464-73. https://doi.org/10.1016/j.jjadhadh.2005.06.010.

8. Engerer JD, Sancaktar E. The effects of partial bonding in load carrying capacity of single lap joints. Int J Adhes Adhes. 2011;31:373-9. https://doi.org/10.1016/j.jjadhadh.2011.01.009.

9. Liu J, Sawa T. Stress analysis and strength evaluation of single-lap band adhesive joints subjected to external bending moments. J Adhes Sci Technol. 1999;13:729-49. https://doi.org/10.1163/156856199X00965.

10. Hellier C. Handbook of Nondestructive Evaluation. McGraw Hill Professional; 2001.

11. Workman GL, Kishoni D, Moore PO. Nondestructive testing handbook, Third Edition: Volume 7, Ultrasonic Testing (UT). n.d.

12. Crowe GV. An introduction to nondestructive testing. n.d.

13. Maeva E, Severina I, Bondarenko S, Chapman G, et al. Acoustical methods for the investigation of adhesively bonded structures: a review. Can J Phys J Can Phys Ott. 2004:82:981-1025.

14. Tattersall HG. The ultrasonic pulse-echo technique as applied to adhesion testing. J Phys Appl Phys. 1973;6:819-32. https ://doi.org/10.1088/0022-3727/6/7/305.

15. Her S-C, Lin Y-C. Assessment of adhesive bond strength using the ultrasonic technique. J Adhes. 2014;90:545-54. https ://doi.org/10.1080/00218464.2013.844691.

16. de Freitas ST, Zarouchas D, Poulis JA. The use of acoustic emission and composite peel tests to detect weak adhesion in composite structures. J Adhes. 2018;94:743-66. https://doi.org/10.1080/00218464.2017.1396975.

17. Goglio L, Rossetto M. Ultrasonic testing of adhesive bonds of thin metal sheets. NDT E Int. 1999;32:323-31. https://doi. org/10.1016/S0963-8695(98)00076-0.

18. Heller K, Jacobs L, Qu J. Characterization of adhesive bond properties using Lamb waves. NDT E Int. 2000;33:555-63. https://doi.org/10.1016/S0963-8695(00)00022-0.

19. Titov SA, Maev RG, Bogachenkov AN. Pulse-echo NDT of adhesively bonded joints in automotive assemblies. Ultrasonics. 2008;48:537-46. https://doi.org/10.1016/j.ultras.2008.07.001.

20. Chakrapani SK, Dayal V, Krafka R, Eldal A. Ultrasonic testing of adhesive bonds of thick composites with applications to wind turbine blades. AlP Conf Proc. 2012;1430:1284-90. https://doi.org/10.1063/1.4716366.

21. Korzeniowski M, PiwowarczykT, Maev RG. Application of ultrasonic method for quality evaluation of adhesive layers. Arch Civ Mech Eng. 2014;14:661-70. https://doi.org/10.1016/j.acme.2013.10.013.

22. You M, Yan Z-M, Zheng X-L, Yu H-Z, Li Z. A numerical and experimental study of gap length on adhesively bonded aluminum double-lap joint. Int J Adhes Adhes. 2007;27:696-702. https://doi.org/10.1016/j.ijadhadh.2007.02.005.

23. Ribeiro FMF, Campilho RDSG, Carbas RJC, da Silva LFM. Strength and damage growth in composite bonded joints with defects. Compos Part B Eng. 2016;100:91-100. https://doi.org/10.1016/j.compositesb.2016.06.060.

24. Ebnesajjad S, Landrock AH. Adhesives Technology Handbook. Elsevier; 2015. https://doi.org/10.1016/c2013-0-18392-4.

25. D14 Committee. Test Method for Apparent Shear Strength of Single-Lap-Joint Adhesively Bonded Metal Specimens by Tension Loading (Metal-to-Metal). ASTM International; n.d. https://doi.org/10.1520/d1002-10.

26. Blackman N, Jack DA. Foreign object identification within a laminated carbon fiber composite using pulse-echo ultrasonics. Conf Proc ASNT 2019 n.d.

27. Volkersen O. Aireraft insurance. Berl Ger Oldenbourg R 1938:41-7.

28. Goland M. The stresses in cemented joints. J Appl Mech. 1944;17:66.

29. Tsai MY, Oplinger DW, Morton J. Improved theoretical solutions for adhesive lap joints. Int J Solids Struct. 1998;35:1 16385. https://doi.org/10.1016/S0020-7683(97)00097-8.

30. Campilho RDSG, others. Repair of composite and wood structures. 2009.

31. Kupski J, de Freitas S, Zarouchas D, Camanho PP, Benedictus R. Composite layup effect on the failure mechanism of single lap bonded joints. Compos Struct. 2019;217:14-26. https://doi.org/10.1016/j.compstruct.2019.02.093.

\section{Publisher's Note}

Springer Nature remains neutral with regard to jurisdictional claims in published maps and institutional affiliations. 